\title{
A portable forced oscillation device for respiratory home monitoring
}

\author{
J. Rigau*, R. Farré*, J. Roca\#, S. Marco", A. Herms`, D. Navajas*
}

A portable forced oscillation device for respiratory home monitoring. J. Rigau, $R$. Farré, J. Roca, S. Marco, A. Herms, D. Navajas. C ERS Journals Ltd 2002.

ABSTRACT: The increase in the prevalence of chronic respiratory diseases has resulted in a rise in health services provided at home. The forced oscillation technique (FOT) proves to be a useful tool when it is desired to assess lung function noninvasively, and particularly for patients in whom spirometry cannot be applied. As no portable FOT device is currently available, the aim of this study was to design and test a portable FOT system for ambulatory and home care applications.

The system devised is based on a microprocessor, which allows online computation of respiratory resistance $(R \mathrm{rs})$ and reactance $\left(X_{\mathrm{rs}}\right)$ and reliability indices. The portable device was compared with a conventional FOT system by using signals from 14 patients with chronic respiratory disease.

This device has the same computation capabilities and flexibility as conventional FOT systems and meets the requirements for home application. Rrs (14.2 \pm $6.0 \mathrm{cmH}_{2} \mathrm{O} \cdot \mathrm{s} \cdot \mathrm{L}^{-1}$, mean $\left.\pm \mathrm{SD}\right)$ and $X_{\mathrm{rs}}\left(-5.3 \pm 2.7 \mathrm{cmH}_{2} \mathrm{O} \cdot \mathrm{s} \cdot \mathrm{L}^{-1}\right)$ measured at $5 \mathrm{~Hz}$ by the portable system virtually coincided with those computed with the reference conventional FOT system: mean differences \pm SD were $0.074 \pm 0.025$ and $0.005 \pm 0.009 \mathrm{cmH}_{2} \mathrm{O} \cdot \mathrm{s} \cdot \mathrm{L}^{-1}$, respectively.

This portable forced oscillation technique device could be a useful tool for monitoring respiratory mechanics in ambulatory and home care applications.

Eur Respir J 2002; 19: 146-150.

The increasing demand for health services due to advances in medicine and ageing of the population has resulted in a progressive rise in patient admission. This is particularly important in chronic respiratory diseases whose prevalence is expected to considerably increase in the near future [1]. To alleviate this problem health services using home care and follow-up programmes are provided [2]. This has led to a more frequent use of portable and home devices in conjunction with advances in telemedicine [3]. In the home care programmes addressed to respiratory disorders, spirometry is the gold standard for measuring pulmonary function in patients with asthma or chronic obstructive pulmonary disease (COPD). Nevertheless, there is a subgroup of patients where lung function is hardly assessed since spirometry is not applicable. Indeed, in many paediatric or elderly patients [4] spirometry cannot be carried out in accordance with the conventional quality standards [5]. Moreover, repeated reproducible spirometry is difficult in asthmatic patients given that forced manoeuvres can alter the bronchomotor tone in these patients [6].

\begin{abstract}
*Unitat de Biofísica i Bioenginyeria, Facultat de Medicina, Universitat de Barcelona, IDIBAPS, Spain. ${ }^{\text {\#Servei }}$ de Pneumologia, Hospital Clínic, Barcelona, Spain. "Dept d'Electrònica, Facultat de Física, Universitat de Barcelona, Spain.
\end{abstract}

Correspondence: R. Farré, Unitat de Biofísica i Bioenginyeria, Facultat de Medicina, Casanova 143, 08036 Barcelona, Spain.

Fax: 34934024516

Keywords: Home health care, lung function, respiratory resistance, telemedicine

Received: May 162001

Accepted after revision August 212001

This work was supported in part by Comisión Interministerial de Ciencia y Tecnología (CICYT, SAF99-0001), by Dirección General de Enseñanza Superior e Investigación Científica (DGESIC, PM98-0027) and by the European Commission (CHRONIC, V Programme, IST_DG XIII, 199912158).
The forced oscillation technique (FOT) is a useful tool for assessing lung function in the situations where spirometry is of difficult or impossible application. FOT is a noninvasive method based on superimposing a high frequency $(>2 \mathrm{~Hz})$ and small amplitude $\left(\sim 1 \mathrm{cmH}_{2} \mathrm{O}\right)$ pressure oscillation at the mouth of the patient during spontaneous breathing [7] and, consequently, patient cooperation is not required. Total respiratory system resistance $(R \mathrm{rs})$ and reactance $(X \mathrm{rs})$ are computed from the oscillatory components of the pressure and flow signals recorded at the mouth. At present, most of the commercially available FOT devices are aimed at lung function laboratory application and they cannot be applied at home because of their dimensions, complexity and cost. However, using FOT at home or in ambulatory applications could be possible should a suitable portable device be available. In addition to meeting the conventional FOT recommendations [8], such an instrument should be easy to operate. Moreover, measurement, robustness and reliability should be enhanced. Accordingly, the aim of this work was to design and test a small and portable FOT device based 


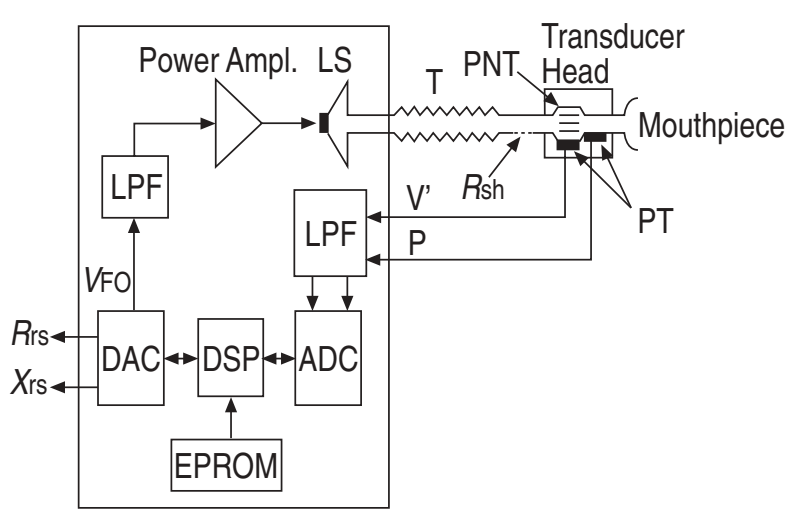

Fig. 1.-Block diagram of the portable forced oscillation technique (FOT) device. DSP: digital signal processor; ADC: analog to digital converter; DAC: digital to analogue converter; EPROM: electronic programmable read-only memory; LPF: low-pass filter; LS: loudspeaker; $R \mathrm{rs}$ : respiratory resistance; $X_{\mathrm{rs}}$ : respiratory reactance; $V_{\text {FO }}$ : forced oscillation excitation; T: flexible tube; $R$ sh: shunt resistance; PT: pressure transducer; PNT: pneumotachograph; $\mathrm{V}^{\prime}$ : flow; P: pressure.

on a microprocessor for ambulatory and home care applications.

\section{Methods}

The portable FOT device (fig. 1) has been designed to compute $R$ rs and $X$ rs in real time. The system is composed of an excitation/transducer block and a microprocessor-based platform for signal generation, data acquisition and online processing. The excitation/ transducer block is based on a small loudspeaker (TS-W161, 6", Pioneer, Des Moines, IA, USA) for generating the pressure oscillation. The excitation signal is stored in the microprocessor internal memory and it is generated with an output channel of a digital to analogue converter (DAC). The resulting signal is analogically low-pass filtered and amplified before driving the loudspeaker. The pressure oscillation generated by the loudspeaker is transmitted to the patient through a flexible tube ( $1 \mathrm{~m}$ length, $2 \mathrm{~cm}$ internal diameter) with a transducer head at the end (fig. 1). The transducer head contains a Fleisch-type pneumotachograph $\left(0.35 \mathrm{cmH}_{2} \mathrm{O} \cdot \mathrm{s} \cdot \mathrm{L}^{-1}\right)$ and two differential pressure sensors (SDXL005D4, $\pm 12.7 \mathrm{cmH}_{2} \mathrm{O}$, SenSym, Puchheim, Germany) with a common-mode rejection ratio of $78 \mathrm{~dB}$ at $5 \mathrm{~Hz}$. A mesh-wire resistor $(R \mathrm{sh})$ of $0.6 \mathrm{cmH}_{2} \mathrm{O} \cdot \mathrm{s} \cdot \mathrm{L}^{-1}$ is connected in parallel at the inlet of the transducer head to avoid rebreathing (fig. 1). The flow and pressure signals are analogically low-pass filtered to prevent aliasing and adapted to the input requirements of an analogue to digital converter (ADC). All analogue low-pass filters are 8-pole, Butterworth-type with a cut-off frequency of $32 \mathrm{~Hz}$. The portable device includes a mesh-wire reference resistance $\left(3.3 \mathrm{cmH} \mathrm{cm}_{2} \mathrm{O} \cdot \mathrm{s} \cdot \mathrm{L}^{-1}\right)$ for calibration, two displays for showing additional data, and three analogue outputs for optional online monitoring of different signals. The core of the microprocessor-based platform (fig. 1) is a digital signal processor (DSP) (TMS320C31,Texas Instruments (TI), Dallas, TX,
USA), with a $48 \mathrm{MHz}$ system clock, which executes the programme stored in an electronic programmable read-only memory (EPROM, 64 Kilobit). The filtered pressure and flow signals are sampled with a 12-bit ADC (TLC2543, TI, USA) and transmitted to the DSP through the serial port. The DSP computes patient impedance in real time and sends the desired output values and the excitation signal to a 12-bit DAC (TLV5614, TI, USA), which generates the corresponding analogue signals.

The system can be programmed with different algorithms depending on the application. The specific implementation was focused on the home assessment of respiratory mechanics in patients with chronic respiratory disease or asthma. For this application, a $5 \mathrm{~Hz}$ excitation frequency was selected [9]. The impedance computation was based on a conventional algorithm described previously [10]. Briefly, the sampled $(100 \mathrm{~Hz})$ pressure and flow signals were filtered with a moving average filter ( 20 points) aimed at separating the breathing noise. The forced oscillation components of pressure and flow were obtained by subtracting the outputs of the moving average filter from the raw signals. The $5 \mathrm{~Hz}$ oscillation components of the resulting signals were determined by Fourier analysis. $R$ rs and $X$ rs were computed online for every new acquired value from the quotient of the Fourier coefficients of oscillatory pressure and flow at the excitation frequency. The resulting $R$ rs and $X$ rs values were low-pass filtered with a 4-pole Butterworth digital filter $(2 \mathrm{~Hz}, 3 \mathrm{~dB})$ to smooth the output signals. The frequency response of the measuring system at the excitation frequency was digitally corrected. The output range of $R$ rs and $X$ rs analogue signals $\left(0-100\right.$ and $\pm 50 \mathrm{cmH}_{2} \mathrm{O} \cdot \mathrm{s} \cdot \mathrm{L}^{-1}$ respectively) were adjusted to fulfill the range required to assess patient impedance and to detect high impedance artifacts such as glottis closure [11]. In addition to computing the online $R$ rs and $X$ rs signals the programme also computed the mean values of $R$ rs and $X \mathrm{rs}$ over $16 \mathrm{~s}$, which are parameters commonly used in FOT measurements [8]. Measurement reliability was evaluated using the coherence function $\left(\gamma^{2}\right)$, computed from the auto-spectra of pressure ( $G \mathrm{PP})$ and flow $(G \mathrm{VV})$ and the cross-spectrum of pressure and flow (GPV) [12]. To this end, the $16 \mathrm{~s}$ filtered pressure and flow signals were divided into 7 blocks of $4 \mathrm{~s}(50 \%$ overlapping). GPP, GVV and GPV at the excitation frequency were computed online for each block as described in [13] and averaged. A coherence function $>0.95$, which is a conventional threshold for $16 \mathrm{~s}$ measurements, was required for measurement acceptance. The mean $R$ rs and $X$ rs values computed over $16 \mathrm{~s}$ were shown in the two displays. Pressure, flow and online $R$ rs signals were sent to the analogue outputs for optional monitoring.

The system devised includes all the excitation, sensors and computation capabilities needed to perform FOT measurements in a portable device. The flexible tube (fig. 1) allows the mouthpiece to be comfortably adapted to the patient when in a sitting or supine position. The FOT excitation subsystem is able to generate an almost constant pressure oscillation for the whole range of expected patient 
resistance $\left(0.7-1.0 \mathrm{cmH}_{2} \mathrm{O}\right.$ peak-to-peak for a $2-50 \mathrm{cmH}{ }_{2} \mathrm{O} \cdot \mathrm{s} \cdot \mathrm{L}^{-1}$ patient resistance). Taking into account the shunt resistance and the pneumotachograph resistance, the device imposes a total load of $<1 \mathrm{cmH}_{2} \mathrm{O} \cdot \mathrm{s} \cdot \mathrm{L}^{-1}$ at the mouth of the patient. The dead space of the system $\left(45 \mathrm{~cm}^{3}\right)$ is low enough to avoid increase in the fractional $\mathrm{CO}_{2}$ concentration at the mouth, given the short duration of a conventional FOT measurement $(<30 \mathrm{~s})$. The operation mode is very simple and consists of two steps. The first one, which is optional, is addressed to verify the system calibration. To this end, the transducer head should be connected to the reference resistance placed in the front panel of the device. According to the stability of the device, a measured value on the reference resistance systematically beyond a $\pm 5 \%$ tolerance should be considered as indicative of system malfunction. In this case, the instructions given to the patient demand him/her to repeat the calibration and, if the difference persists, to call the hospital staff in charge of the home care programme. The second step, which is the patient measurement, only requires the patient to push a "start" button and breathe normally through the mouthpiece for $20 \mathrm{~s}$ (4 s for subject adaptation and $16 \mathrm{~s}$ for $R \mathrm{rs}$ and $X \mathrm{rs}$ measurement) while holding his/her cheeks. If the coherence is lower than the acceptance threshold (0.95), the result is rejected and the device demands another measurement by means of a red light at the front panel.

The performance of the DSP-based platform of the portable FOT device was evaluated when subjected to signals typically found in the clinical application. To this end, the pressure, flow, $R$ rs and $X$ rs signals corresponding to a previous FOT study [9] in 14 patients with severe chronic respiratory disease were used. Eight of the patients suffered from COPD and the other six patients presented a restrictive ventilatory defect due to chest wall disease. The anthropometric and lung function data of these patients are described in detail elsewhere [9]. The patients were in a stable clinical condition at the time of the study and measurements were carried out in a sitting posture during normal breathing. The study was approved by the Ethics Committee of the Hospital Clinic Provincial, Barcelona, Spain and informed consent was obtained from each patient. For the evaluation of the DSP-platform of the portable FOT device, the execution programme was slightly modified to send the online $R$ rs and $X$ rs signals to the analogue outputs. The previously stored flow and pressure signals were analogically reproduced by a personal computer (PC) with an analogue-digital/digital-analogue (AD/DA) board and were fed into the AD converter of the portable FOT device. The corresponding $R$ rs and $X$ rs analogue signals computed by the DSP-platform were acquired by the PC and compared with the reference $R$ rs and $X$ rs signals stored. For each patient, the time course of $R$ rs and $X$ rs along the breathing cycle was compared as well as the mean values computed over a $16 \mathrm{~s}$ period. The mean values obtained from the portable FOT device were compared with the corresponding mean values of the reference signals using linear regression and the BLAND and ALTMAN analysis [14] (mean difference and limits of agreement defined as mean \pm 2 SD of differences).

The repeatability of the measurements obtained with the whole portable device was assessed with measurements on the reference resistance and on patients with COPD. First, one calibration measurement was carried out on 21 different days. Second, five consecutive resistance measurements (16 s each) were performed with the portable device in eight patients with severe COPD (forced expiratory volume in one second $=30.4 \pm 26.7 \%$ predicted). The coefficient of variation of the resistance in each patient was computed from the five measured values.

\section{Results}

The portable device was able to perform the online tracking of the changes of $R \mathrm{rs}$ and $X \mathrm{rs}$ along the breathing cycle, as shown in the example of fig. 2 corresponding to the FOT measurement of a patient with COPD. Rrs exhibited higher values during expiration than inspiration, whereas $X$ rs showed more negative values during expiration than inspiration. As expected, $R$ rs and $X$ rs signals computed online by the portable system virtually coincided with the stored reference ones (fig. 2). The coherence function in this example was 0.99 indicating good reliability of the data. Accordingly, this measurement was accepted. Figure 3 illustrates the occurrence of an artifact during a FOT measurement. In this case, the patient closed the glottis as reflected by the flow signal. $R$ rs
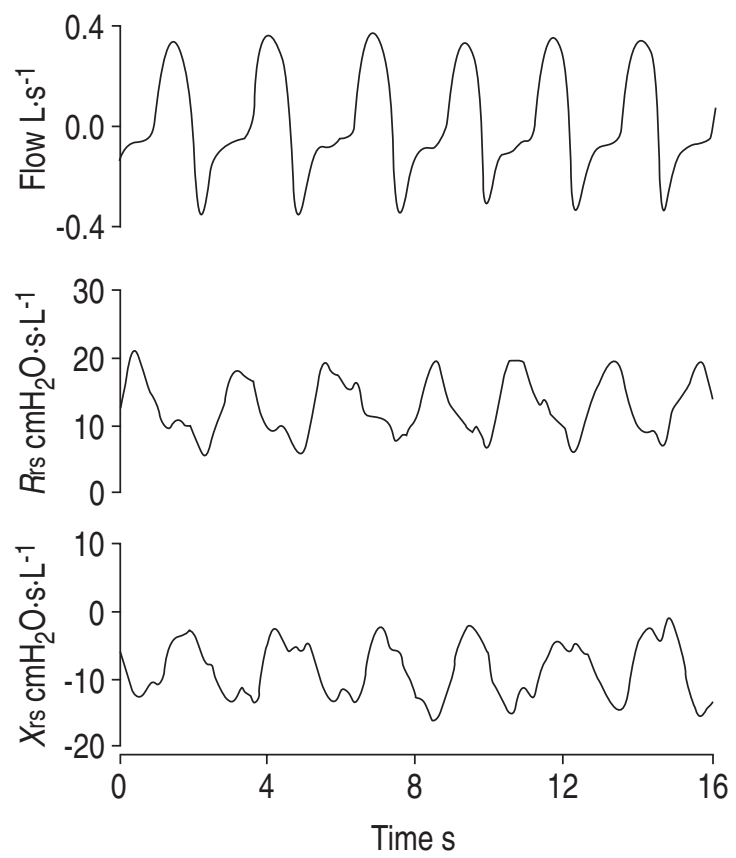

Fig. 2.-Example of flow, respiratory resistance $(R \mathrm{rs})$ and reactance $(X \mathrm{rs})$ signals in a forced oscillation technique (FOT) measurement on a patient with chronic obstructive pulmonary disease. The flow signal (positive during inspiration) was digitally filtered to eliminate the forced oscillation. The $R$ rs and $X_{\text {rs }}$ signals computed online by the portable FOT device (thick lines) and the reference signals (thin lines) are indistinguishable. 


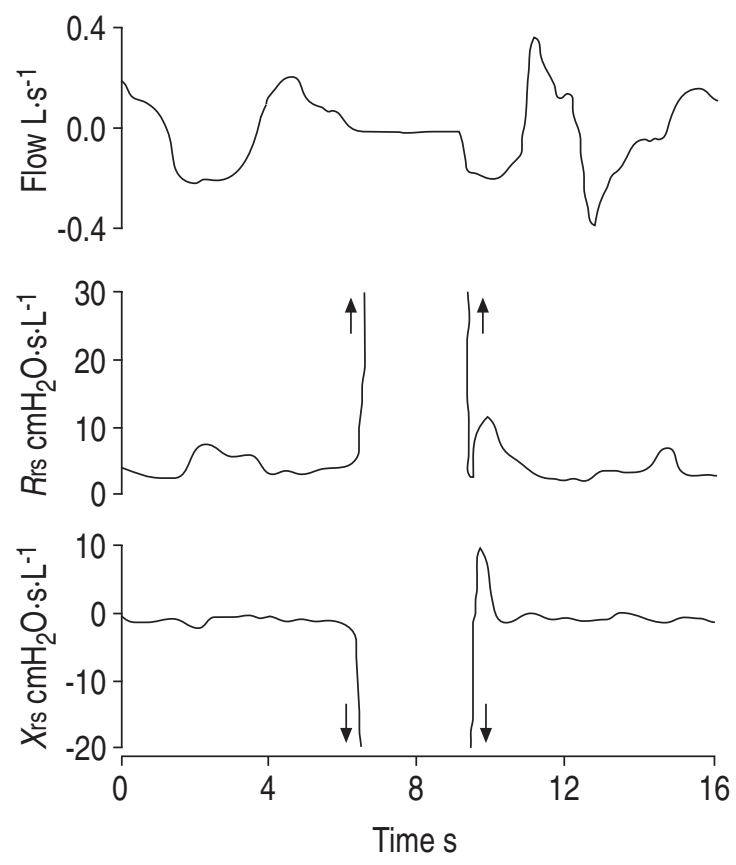

Fig. 3.-Example of an artefact during a forced oscillation technique (FOT) measurement. As reflected by the flow signal, a glottis closure occurred at time $6-10 \mathrm{~s}$ during the measurement. Respiratory resistance $(R \mathrm{rs})$ and reactance $(X \mathrm{rs})$ were $>100 \mathrm{cmH} \mathrm{cm}_{2} \mathrm{O} \cdot \mathrm{s} \cdot \mathrm{L}^{-1}$ and $<-50 \mathrm{cmH} \mathrm{Cm}_{2} \mathrm{O} \cdot \mathrm{s} \cdot \mathrm{L}^{-1}$ respectively as a result of the glottis occlusion. This $16 \mathrm{~s}$ measurement was automatically rejected by the portable FOT device since $\gamma^{2}=0.76$.

and $X$ rs underwent a huge increase and decrease, respectively, during the artifact. The resulting coherence $\left(\gamma^{2}=0.76\right)$ was below the acceptance threshold and, consequently, the result was automatically rejected and the device demanded a subsequent measurement.

The results obtained when comparing the 16-s mean of $R$ rs and $X$ rs computed by the DSP platform (RDSP, $X \mathrm{DSP})$ with the corresponding mean values of the stored signals $(R, X)$ are shown in fig. 4. The linear regression of both signals $\left(R \mathrm{DSP}=0.115 \mathrm{cmH}_{2} \mathrm{O} \cdot \mathrm{s} \cdot \mathrm{L}^{-1}+0.997 * \mathrm{R}, \mathrm{r}^{2}>0.999 ; X \mathrm{DSP}=\right.$ $\left.-0.023 \mathrm{cmH}_{2} \mathrm{O} \cdot \mathrm{s} \cdot \mathrm{L}^{-1}+0.997 * \mathrm{X}, \mathrm{r}^{2}>0.999\right)$ almost coincided with the identity line. The Bland and Altman analysis showed a good agreement in both $R$ rs and $X$ rs. The mean differences for $R$ rs and $X$ rs were 0.074 and $0.005 \mathrm{cmH}_{2} \mathrm{O} \cdot \mathrm{s} \cdot \mathrm{L}^{-1}$, respectively. The limits of agreement (in $\mathrm{cmH}_{2} \mathrm{O} \cdot \mathrm{s} \cdot \mathrm{L}^{-1}$ ) were 0.024 and 0.124 for $R$ rs and -0.033 and 0.023 for $X$ rs. These mean differences and limits of agreement had no clinical significance when compared with the values (mean \pm SD) of $R \mathrm{rs}$ and $X \mathrm{rs}\left(14.2 \pm 6.0\right.$ and $-5.3 \pm 2.7 \mathrm{cmH}_{2} \mathrm{O} \cdot \mathrm{s} \cdot \mathrm{L}^{-1}$, respectively) measured in these chronic respiratory patients.

The portable device provided stable resistance values when the reference resistance was measured on 21 different days: mean value of $3.35 \mathrm{cmH}_{2} \mathrm{O} \cdot \mathrm{s} \cdot \mathrm{L}^{-1}$, coefficient of variation of $1.1 \%$ and range: 3.30 $3.43 \mathrm{cmH}{ }_{2} \mathrm{O} \cdot \mathrm{s} \cdot \mathrm{L}^{-1}$. The mean coefficient of variation in the resistance measured in 8 COPD patients was $8 \%$ (range $3-15 \%$ ) and was similar to the ones provided in the literature.

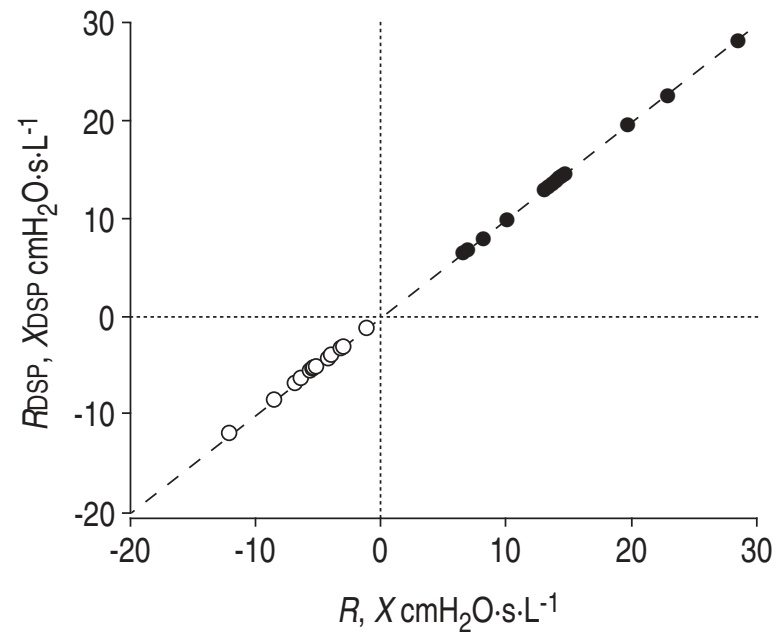

Fig. 4. - Mean respiratory resistance $(\bullet)$ and reactance $(\bigcirc)$ values over a $16 \mathrm{~s}$ period computed by the portable forced oscillation technique (FOT) device (RDSP, XDSP) versus the corresponding reference values $(R, X)$ for the 14 patients with chronic respiratory disease. Dashed line is the identity line. DSP: digital signal processor.

\section{Discussion}

The present authors developed and evaluated a portable FOT device able to compute the mechanical resistance and reactance of the respiratory system in real time. The device includes all the instrumentation needed to perform conventional FOT measurements and meets the general recommendations for a FOT apparatus [8]. Moreover, the device calibration and operation is easily carried out and artefactual data are automatically rejected.

At present most of the commercially available FOT devices are based on a general-purpose PC for controlling the excitation system, acquiring the signals and processing the data. They are programmed with complex algorithms such as pseudorandom noise excitation for simultaneously assessing $R$ rs and $X$ rs at multiple frequencies, for computing the frequency of resonance and for differentiating between inspiration and expiration. Although these devices have considerable facilities in the computation algorithm, their characteristics are not addressed to those applications where a simple and portable measuring system is required, such as home care and ambulatory applications. Other simpler FOT devices are based on monofrequency oscillation or on computing the amplitude of respiratory impedance [15]. Although these systems had been useful for assessing airway obstruction, particularly during sleep [16,17], they are not able to change the oscillation frequency or to apply multifrequency oscillation and their computation algorithm does not provide selective information on $R$ rs and $X$ rs.

The FOT system developed in this work is aimed at home and ambulatory applications where small and compact devices are required. The core of this prototype is based on a microprocessor to achieve the same software capabilities of the commercial FOT devices (multifrequency, mean values, inspiratory/expiratory 
phases, reliability indices, etc.). Modifying the software, e.g. to include the selection of different oscillation frequencies, would only require changing the programme stored in the memory (EPROM, fig. 1). Software flexibility facilitates the implementation of new applications and updating to future FOT standards or regulations [8]. This DSP-based device may also be used in other applications such as monitoring home ventilation [18] or simplified home polysomnography. In these applications, the computation algorithm could include a routine to compensate for leaks in the mask [9] or to simplify FOT measurements by placing the transducer-head away from the patient [19]. From the practical viewpoint of respiratory monitoring, it is worth noting that the designed FOT device includes all the instrumentation (pneumotachograph, pressure transducers and a programmable processor) for implementing a conventional digital spirometer provided that the pneumotachograph performance is in keeping with the range of measured flow. Accordingly, FOT and forced spirometry could be combined in the same portable device to perform more complete lung function assessment at home.

In conclusion, this study demonstrates that FOT can be implemented in a portable system. The device developed is able to compute $R$ rs and $X$ rs in real time and combines the computation capabilities and flexibility of conventional systems, and the advantages of low-cost and portability. Given its characteristics and performance this device is particularly suited for monitoring respiratory mechanics in home care and ambulatory applications. Moreover, this microprocessor-based device could include a communication interface with internet capabilities. This would provide online interaction between the patient at home and the health provider [3] for a suitable follow-up of his/her disease. This application is in keeping with the current trend in providing health care at the patient's home. It could be useful for the daily monitoring of variability in airway obstruction in patients with asthma and for adjusting the treatment accordingly [20].

Acknowledgements. The authors would like to thank M.A. Rodriguez for his technical assistance.

\section{References}

1. Murray CJ, Lopez AD. Alternative projections of mortality and disability by cause 1990-2020: Global Burden of Disease Study. Lancet 1997; 349: 1498 1504.

2. Clini E, Vitacca M, Foglio K, Simoni P, Ambrosino $\mathrm{N}$. Long-term home care programmes may reduce hospital admissions in COPD with chronic hypercapnia. Eur Respir J 1996; 9: 1605-1610.

3. Finkelstein J, Cabrera MR, Hripcsak G. Internetbased home asthma telemonitoring: can patients handle the technology? Chest 2000; 117: 148-155.

4. Carvalhaes-Neto $\mathrm{N}$, Lorino $\mathrm{H}$, Gallinari $\mathrm{C}$, et al.
Cognitive function and assessment of lung function in the elderly. Am J Respir Crit Care Med 1995; 152: 1611-1615.

5. American Thoracic Society. Standardization of Spirometry. 1994 update. Am J Respir Crit Care Med 1995; 152: $1107-1136$

6. Gayrard P, Orehek J, Grimaud C, Charpin J. Bronchoconstrictor effects of a deep inspiration in patients with asthma. Am Rev Respir Dis 1975; 111: 433-439.

7. Navajas D, Farré R. Oscillation mechanics. In: MilicEmili J, ed. European Respiratory Monograph. European Respiratory Society Journals Ltd., 1999, pp. 112-113.

8. Van de Woestijne KP, Desager KN, Duiverman EJ, Marchal F. Recommendations for measurement of respiratory input impedance by means of the forced oscillation method. Eur Respir Rev 1994; 4: 235-237.

9. Farré R, Gavela E, Rotger M, Ferrer M, Roca J, Navajas D. Noninvasive assessment of respiratory resistance in severe chronic respiratory patients with nasal CPAP. Eur Respir J 2000; 15: 314-319.

10. Farré R, Peslin R, Rotger M, Navajas D. Inspiratory dynamic obstruction detected by forced oscillation during CPAP. A model study. Am J Respir Crit Care Med 1997; 155: 952-956.

11. Badia JR, Farré R, Montserrat JM, et al. Forced oscillation technique for the evaluation of severe sleep apnoea/hypopnoea syndrome: a pilot study. Eur Respir J 1998; 11: 1128-1134.

12. Michaelson ED, Grassman ED, Peters WR. Pulmonary mechanics by spectral analysis of forced random noise. J Clin Invest 1975; 56: 1210-1230.

13. Farré R, Navajas D, Rotger M. Optimised algorithm to compute respiratory impedance by pseudorandom forced excitation. Med Biol Eng Comput 1991; 29: 615-617.

14. Bland JM, Altman DG. Statistical methods for assessing agreement between two methods of clinical measurement. Lancet 1986; 1: 307-310.

15. Farré R, Rotger M, Montserrat JM, Navajas D. Analog circuit for real-time computation of respiratory mechanical impedance in sleep studies. IEEE Trans Biomed Eng 1997; 44: 1156-1159.

16. Badia JR, Farré R, Kimoff RJ, et al. Clinical application of the forced oscillation technique for CPAP titration in the sleep apnea/hypopnea syndrome. Am J Respir Crit Care Med 1999; 160: 15501554.

17. Navajas D, Farré R, Rotger M, Badia JR, Puig-deMorales M, Montserrat JM. Assessment of airflow obstruction during CPAP by means of forced oscillation in patients with sleep apnea. Am J Respir Crit Care Med 1998; 157: 1526-1530.

18. Farré R, Mancini M, Rotger M, Roca J, Navajas D. Oscillatory resistance measured during noninvasive proportional assist ventilation. Am J Respir Crit Care Med 2001; 164: 790-794.

19. Farré R, Rigau J, Montserrat JM, Ballester E, Navajas D. Evaluation of a simplified oscillation technique for assessing airway obstruction in sleep apnoea. Eur Respir J 2001; 17: 456-461.

20. Que C-L, Kenyon CM, Olivenstein R, Macklem PT, Maksym GN. Homeokinesis and short-term variability of human airway caliber. J Appl Physiol 2001; 91: 1131-1141. 